\title{
Physicochemical Properties and Antioxidant Activity of Chitin and Chitosan Prepared from Pacific White Shrimp Waste
}

\author{
Trang Si Trung and Huynh Nguyen Duy Bao \\ Faculty of Food Technology, Nha Trang University, 02 Nguyen Dinh Chieu, Nha Trang 57000, Vietnam \\ Correspondence should be addressed to Huynh Nguyen Duy Bao; hndbao@yahoo.com
}

Received 18 August 2014; Accepted 21 January 2015

Academic Editor: J. F. Vliegenthart

Copyright (C) 2015 T. Si Trung and H. N. D. Bao. This is an open access article distributed under the Creative Commons Attribution License, which permits unrestricted use, distribution, and reproduction in any medium, provided the original work is properly cited.

\begin{abstract}
Chitin and chitosan, valuable marine biopolymers, recovered from shrimp waste, are an abundant by-product of the shrimp processing industry in Vietnam, at an estimated 200000 metric tons per year. The obtained chitin and chitosan are characterized by their purity and functional properties. The polymers show good quality with low residual ash and protein content $(<1 \%)$. The antioxidant potency of chitosan is evaluated by several different in vitro systems, including 1,1-diphenyl-2-picrylhydrazyl (DPPH) free radical scavenging, total reducing power, and inhibition of lipid peroxidation. The DPPH free radical scavenging, total reducing power, and lipid peroxidation inhibition activities of chitosan at varying concentration $(0.125$ to $1.0 \mathrm{mg} / \mathrm{mL})$ range from 3.7 to $16.8 \%$, 0.05 to 0.15 , and 1.7 to $15.1 \%$, respectively. This study demonstrates that chitin and chitosan, of good quality and having characteristics compatible with a broad range of applications, can be prepared from white shrimp waste.
\end{abstract}

\section{Introduction}

Chitin, a linear polymer of $\beta$ (1-4) linked 2-acetamido-2deoxy-D-glucopyranose, is one of the most abundant natural polymers, found in almost all crustaceans. Chitin, especially its deacetylated form, and chitosan are well known marine biopolymers, having many applications in the food industry, agriculture, biotechnology, cosmetics, medicine, and also waste treatment [1-4]. The reactive functional groups of chitosan include an amino group and both primary and secondary hydroxyl groups at C-2, C-3, and C-6 positions, respectively. The amino contents of chitosan are the main factors influencing their structures and physicochemical properties and are correlated with their chelation, flocculation, and biological functions [5]. Chitosan has attracted considerable interest, not only due to being an underutilized resource but also due to its biological behaviors, namely, antioxidant, antimicrobial, hypocholesterolemic, immunityenhancing and antitumor activity, drug delivery, and its capacity to accelerate calcium and ferrum absorption, and so forth [1-3]. The antioxidant properties of chitosan have been studied in vitro and in vivo. The antioxidant effects of chitosan on the oxidation of lard and crude rapeseed oil were demonstrated by Liu [6] who reported that chitosan could significantly reduce serum free fatty acids and malondialdehyde concentrations, elevate superoxide dismutases, and display catalase and glutathione peroxidase activities, the latter being the major antioxidant enzymes in the body. This indicates that chitosan regulated the antioxidant enzyme activities and reduced lipid peroxidation. The biological activities of chitosan and its derivatives correlated with their structures and physicochemical properties [7].

A major source for the large scale production of chitin and chitosan is crustacean processing waste (shrimp, krill, and crab shells). The structures and physicochemical properties of chitin and chitosan depend on both the sources and the production conditions [8-11].

Vietnam is one of the foremost countries involved in shrimp aquaculture [12]. Shrimp are usually peeled in standard seafood processing factories to obtain shrimp meat for export, and the leftover shells and heads, approximately 35$45 \%$ of the total weight, are considered to be waste. As a result, shrimp processing leads to massive amounts of shrimp biowaste in Vietnam estimated to be more than 200,000 metric tons (wet weight) per year [13]. To date, the shrimp waste in Vietnam has been used primarily for the preparation 
of chitin and chitosan. The potential applications of chitin and chitosan depend on their physicochemical properties and biological activities. However, the information that has been prepared from Vietnamese shrimp waste on the physicochemical properties and biological activities of chitin and chitosan prepared from Vietnamese shrimp waste is limited. To our knowledge, no systematic study has been published. The present study, therefore, was conducted to investigate the physicochemical properties and antioxidant activities of chitin and chitosan prepared from Vietnamese shrimp waste.

\section{Materials and Methods}

2.1. Materials and Chemicals. White shrimp waste was collected from a seafood processing factory in Khanh Hoa Province, Central Vietnam. The cold shrimp waste was transported to a laboratory under ice. The waste was washed in running water and ground in a knife mill to obtain pieces of 0.3 to $0.5 \mathrm{~cm}$. Portions of $1000 \mathrm{~g}$ were packed in plastic bags and frozen at $-20^{\circ} \mathrm{C}$ until required.

Sodium hydroxide and hydrochloric acid were purchased from Viet Tri Chemical Joint Stock Company (Phu Tho, Vietnam). All other chemicals were of analytical grade and were purchased from Sigma-Aldrich (St. Louis, MO, USA).

\subsection{Chitin and Chitosan Recovery from Shrimp Waste. Chitin} was prepared from shrimp waste by combining enzymatic and chemical treatment [13]. $10 \mathrm{~kg}$ of ground shrimp waste was thawed and mixed thoroughly with $5 \mathrm{~L}$ of warm distilled water $\left(50^{\circ} \mathrm{C}\right)$. Deproteinization was carried out using the enzyme alcalase (food grade $2.4 \mathrm{AU} / \mathrm{g}$ ) generously provided by Novozymes (Denmark). The enzyme is produced from the submerged fermentation of Bacillus licheniformis.

The deproteinization took place in plastic tanks as follows: percentage enzyme/wet waste, $0.2 \% \mathrm{v} / \mathrm{w}, \mathrm{pH} 8$, and $55^{\circ} \mathrm{C}$ treatment duration for $8 \mathrm{~h}$. The adjustment of $\mathrm{pH}$ was achieved by using $1 \mathrm{~N} \mathrm{NaOH}$. The reaction was stopped for $15 \mathrm{~min}$ after reaching $85^{\circ} \mathrm{C}$. Next, the enzyme treated waste was immersed in $2 \% \mathrm{NaOH}$ for $12 \mathrm{~h}(1 / 5 \mathrm{w} / \mathrm{v})$ at room temperature in order to remove the remaining protein. The resulting solids were washed until neutral. Finally, the sample was demineralized by soaking it in a $4 \% \mathrm{HCl}$ solution for $12 \mathrm{~h}(1 / 5, \mathrm{w} / \mathrm{v})$ at room temperature; then it was washed to obtain the chitin.

Chitosan was prepared from chitin by a chemical method, in $50 \%(\mathrm{v} / \mathrm{v}) \mathrm{NaOH}$ at $65^{\circ} \mathrm{C}$ for $20 \mathrm{~h}$, and then washed to a neutral $\mathrm{pH}$ and dried to obtain chitosan [14].

2.3. Characterization of Chitin and Chitosan. The crystallinity of the chitin and chitosan was measured by a Bruker Advance D8 X-ray diffractometer at a scanning speed of $2^{\circ} 2 \theta / \mathrm{min}$ within a range from $5^{\circ}$ to $30^{\circ}$. NMR- $1 \mathrm{H}$ spectra were recorded for both chitin and chitosan in concentrated $\mathrm{DCl}(35 \% \mathrm{w} / \mathrm{v})$ at $300 \mathrm{~K}$ on a $300 \mathrm{MHz}$ Bruker Advance DPX spectrometer [15]. The IR spectra of the chitin and chitosan were measured from 4000 to $400 \mathrm{~cm}^{-1}$ with a Bruker Tensor 37 FT-IR spectrophotometer. The degree of deacetylation of chitosan was measured by the UV method [16]. A bulk density was assayed following the procedure of Cho et al. [17] and was computed as $\mathrm{g} / \mathrm{mL}$. The water binding capacity was measured using the method of No et al. [18].

2.4. Determination of 2,2-Diphenyl-1-picrylhydrazyl Radical Scavenging Activity. DPPH radical scavenging activity was determined following the method of Fu et al. [19] with a slight modification. Briefly, reaction mixtures, containing $1 \mathrm{~mL}$ of a chitosan sample $(1.0-2.0 \mathrm{mg} / \mathrm{mL})$ in $0.5 \%$ acetic acid solution, $1 \mathrm{~mL}$ ethanol, and $1 \mathrm{~mL}$ of $0.1 \mathrm{mM}$ DPPH ethanol solution, were raised to a final volume of $4 \mathrm{~mL}$ by $0.5 \%$ acetic acid solution in test tubes. The mixtures were mixed thoroughly and then kept at $25^{\circ} \mathrm{C}$ for $30 \mathrm{~min}$ in the dark. The absorbance of the mixtures was measured at $517 \mathrm{~nm}$ against a blank without DPPH using a Shimadzu model mini 1240 UVVis spectrophotometer (Kyoto, Japan). BHT was used for comparison.

The DPPH radical scavenging activity was calculated using the following equation:

$$
\begin{gathered}
\text { DPPH radical scavenging activity (\%) } \\
=\left(\frac{A_{\text {control }}-A_{\text {sample }}}{A_{\text {control }}}\right) \times 100,
\end{gathered}
$$

where $A_{\text {control }}$ and $A_{\text {sample }}$ are absorbances of a control mixture without antioxidant and a mixture containing antioxidant, respectively.

2.5. Determination of Total Reducing Power Ability. The total reducing power ability was measured as described by Oyaizu [20] with a slight modification as follows. Briefly, a $0.5 \mathrm{~mL}$ portion of $1 \%$ potassium ferricyanide was mixed with $0.5 \mathrm{~mL}$ of a chitosan sample $(1.0-2.0 \mathrm{mg} / \mathrm{mL})$ in $0.5 \%$ acetic acid solution, and each was raised in test tubes to a final volume of $1.5 \mathrm{~mL}$ with the addition of a $0.2 \mathrm{M}$ sodium phosphate buffer ( $\mathrm{pH}$ 6.6). The mixtures were incubated at $50^{\circ} \mathrm{C}$ for $20 \mathrm{~min}$ and subsequently $0.5 \mathrm{~mL}$ of $10 \%$ trichloroacetic acid was added, followed by the addition of $2 \mathrm{~mL}$ of distilled water and $400 \mu \mathrm{L}$ of $0.1 \%$ of ferric chloride. The reaction mixtures were then centrifuged at $3,000 \mathrm{rpm}$ for $10 \mathrm{~min}$. The absorbance of the supernatant was measured at $700 \mathrm{~nm}$ against a blank using the spectrophotometer. Increased absorbance indicated increased reducing power. BHT was used for comparison.

2.6. Determination of Lipid Peroxidation Inhibition Activity. Lipid peroxidation inhibition activity was determined as described by Bao et al. [21] with a slight modification. Briefly, a $50 \mathrm{~g}$ portion of tuna (Thunnus albacares) dark muscle was homogenized in $500 \mathrm{~mL}$ of a $1.15 \% \mathrm{KCl}$ aqueous solution at $13000 \mathrm{rpm}$ for $5 \mathrm{~min}$ with a model PRO250 Homogenizer (PRO Scientific Inc., USA) to produce muscle homogenate of $10 \%$. The mixtures containing $9 \mathrm{~mL}$ of the homogenate and $1 \mathrm{~mL}$ of either $0.5 \%$ acetic acid solution or one of the chitosan solutions $(1.0-2.0 \mathrm{mg} / \mathrm{mL})$ were initiated by the addition of $45 \mu \mathrm{L}$ of $\mathrm{FeCl}_{3} /$ sodium ascorbate $(1: 1, \mathrm{v} / \mathrm{v})$ held in $25 \mathrm{~mL}$ Erlenmeyer flasks. The mixtures in $25 \mathrm{~mL}$ Erlenmeyer flasks were subsequently incubated at $37^{\circ} \mathrm{C}$ for $1 \mathrm{~h}$. Thiobarbituric acid reactive substances (TBARS) formation in the mixtures during incubation was determined spectrophotometrically 
according to the procedure of Uchiyama and Mihara [22]. Absorbances at $535 \mathrm{~nm}$ of the reaction products in $n$-butanol were measured with the spectrophotometer.

Lipid peroxidation inhibition activity was calculated using the following equation:

Lipid peroxidation inhibition activity (\%)

$$
=\left(\frac{A_{\text {control }}-A_{\text {sample }}}{A_{\text {control }}}\right) \times 100 \text {, }
$$

where $A_{\text {control }}$ is the absorbance of a control mixture, without the chitosan, and $A_{\text {sample }}$ is the absorbance of a mixture containing the chitosan solution.

2.7. Statistical Analyses. Statistical analysis of the data was performed using $\mathrm{R}$ software for Windows version 3.1.1 (http://cran.r-project.org/bin/windows/base/). Significant differences were determined by one-way ANOVA, and Tukey's Multiple Comparisons of Means test was used to determine the statistical difference between the samples at $P<0.05$.

\section{Results and Discussion}

3.1. Physicochemical Properties of Chitin, Chitosan Recovered from White Shrimp Waste. Earlier studies have demonstrated that the physicochemical characteristics of chitosan affect its functional properties $[17,18]$. The present study shows that degree of deacetylation, bulk density, and water binding capacity of chitosan was $87.0 \pm 2.2 \%, 0.57 \pm 0.02(\mathrm{~g} / \mathrm{mL})$, and $508 \pm 26$ (\%), respectively. The crystal structures of chitin and chitosan are characterized by XRD measurements (Figure 1). The diffraction pattern of the chitin shows strong reflections at $2 \theta$ around $9-10^{\circ}$ and $2 \theta$ of $20-21^{\circ}$ and minor reflections at higher $2 \theta$ values, for example, at $26.4^{\circ}$ (Figure 1(a)). The peaks are high and sharp, indicating a highly ordered crystal structure of $\alpha$-chitin. It is clearly distinguished from $\beta$-chitin prepared from squid pens as reported by previous work [23]. However, after chemical deacetylation, the two sharp peaks became lower and broader, while the minor peaks disappeared in the diffraction pattern of the chitosan, indicating a lower level of crystallinity or a more amorphous structure of the chitosan (Figure 1(b)). A similar phenomenon was observed in previous works for chitin obtained from lobster, crab shells, and squid pens [8].

Infrared (IR) spectroscopy is one of the most important and widely used analytical techniques available to characterize the chemical structure of chitin and chitosan. The FTIR spectra of chitin and chitosan are shown in Figure 2. The spectrum of chitin shows the usual characteristic stretching vibration bands at $3440 \mathrm{~cm}^{-1}(\mathrm{O}-\mathrm{H}), 2880 \mathrm{~cm}^{-1}(\mathrm{C}-\mathrm{H}), 1660$ and $1626 \mathrm{~cm}^{-1}$ (amide I), $1558 \mathrm{~cm}^{-1}$ (amide II), $1379 \mathrm{~cm}^{-1}$ $(\mathrm{C}-\mathrm{H})$, and $950-1200 \mathrm{~cm}^{-1}$ (C-O-C) and (C-O) (Figure 2(a)). In the case of chitosan, the FTIR spectrum is similar to that of chitin (Figure 2(b)). However, compared with the spectrum of chitin, the representative peaks at $1560 \mathrm{~cm}^{-1}$ (amide II) and $1315 \mathrm{~cm}^{-1}$ (amide III) are significantly decreased or removed completely after the $\mathrm{N}$-deacetylation of chitin, confirming

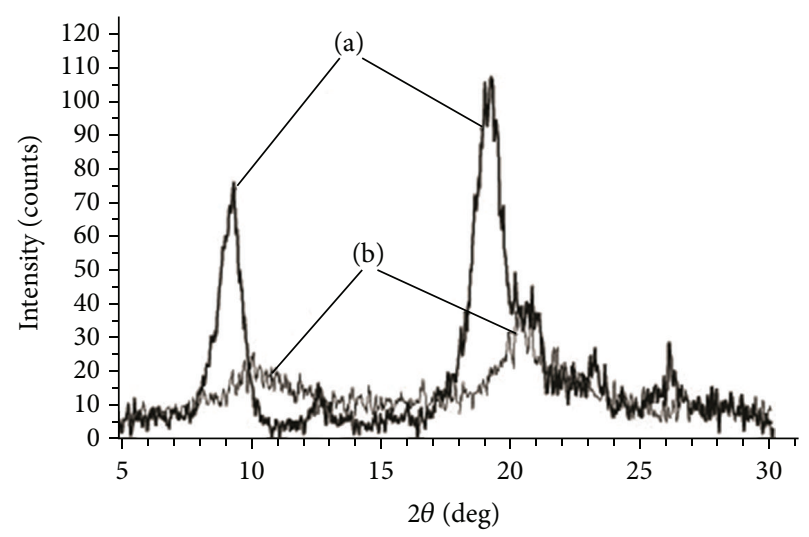

FIGURE 1: XRD patterns of chitin (a) and chitosan (b) prepared from white shrimp waste.

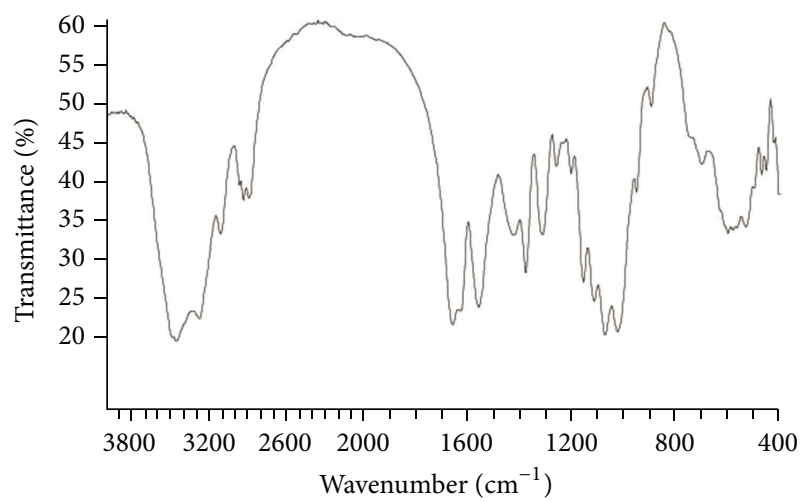

(a)

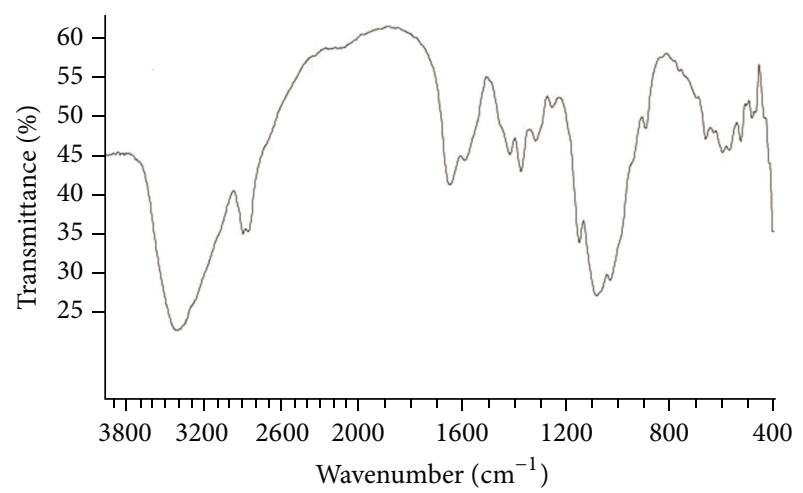

(b)

FIGURE 2: FTIR spectra of chitin (a) and chitosan (b) prepared from white shrimp waste.

the almost total conversion to chitosan and reflecting a high degree of deacetylation. Our IR results concur with those of chitin and chitosan preparations from shrimp sources reported from previous authors $[8,24]$.

The nuclear magnetic resonance (NMR) spectroscopy is a powerful method used to characterize the chemical composition of chitin and chitosan. Chitin is not soluble in most common organic solvents. However, chitin can be 


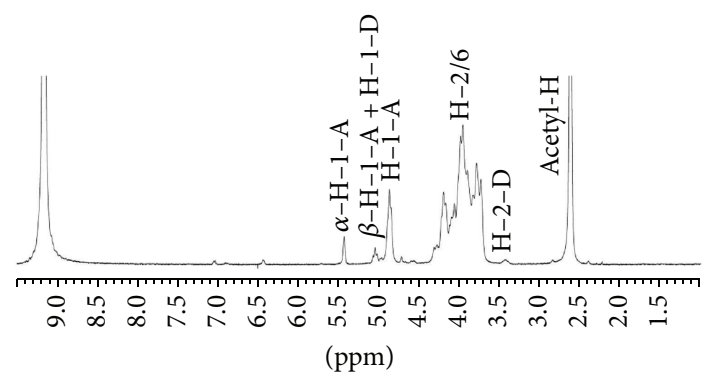

(a)

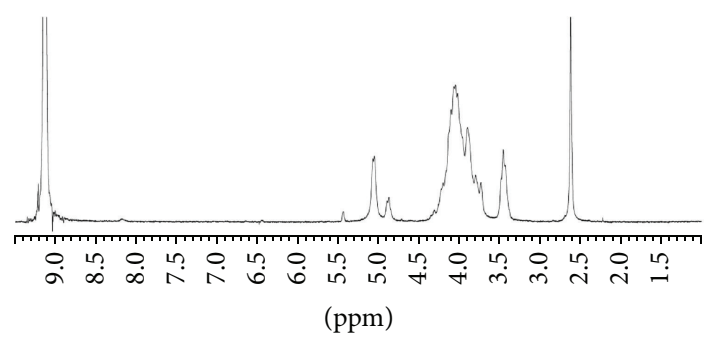

(b)

FIGURE 3: ${ }^{1} \mathrm{H}$ NMR spectrum of chitin isolated from white shrimp in concentrated $\mathrm{DCl}(37 \%)$ at $25^{\circ} \mathrm{C}$ (a); of chitosan prepared from white shrimp chitin in $\mathrm{CD}_{3} \mathrm{COOD} / \mathrm{D}_{2} \mathrm{O}$ at $90^{\circ} \mathrm{C}(\mathrm{b})$.

dissolved in concentrated $\mathrm{HCl}$ with an insignificant deacetylation of acetyl groups. Therefore, the ${ }^{1} \mathrm{H}$ NMR of chitin in concentrated DCl (as shown in Figure 3(a)) can be used to determine the degree of acetylation (DA) of chitin. The DA of chitin isolated from white shrimp is calculated using the equation proposed by Einbu and Varrum [25] as 0.95. It means that the chemical structure of chitin has caused minimal damage during isolation and that the chitin is then suitable for high yield $N$-acetyl glucosamine production [25].

Figure 3(b) shows the ${ }^{1} \mathrm{H}$ NMR spectrum of chitosan prepared from white shrimp chitin. The calculation of DA from this spectrum used a method proposed by Vårum et al. [15] and gave a value of 0.195 . Therefore, the chitosan prepared has a relatively low DA.

\subsection{Antioxidant Activity of Chitosan Recovered from White} Shrimp Waste. The DPPH radical scavenging activity of the chitosan and BHT and its different concentrations is presented in Figure 4. The DPPH radical scavenging activity of the chitosan was significantly lower $(P<0.05)$ than that of $\mathrm{BHT}$ at the same concentration. The activity varied from 3.7 to $16.8 \%$, which corresponds to 1.0 to $2.0 \mathrm{mg}$ of the chitosan per $\mathrm{mL}$. Chitosan scavenges various free radicals through the action of nitrogen on the C-2 position of the chitosan [26]. The scavenging mechanism of chitosan was suggested by Xia et al. [7]. The nitrogen of amino groups has a lone pair of electrons; it can attach to a proton released from acidic solution to form ammonium $\left(\mathrm{NH}_{3}{ }^{+}\right)$groups. The free radicals can react with the hydrogen ion from the $\mathrm{NH}_{3}{ }^{+}$to form a stable molecule.

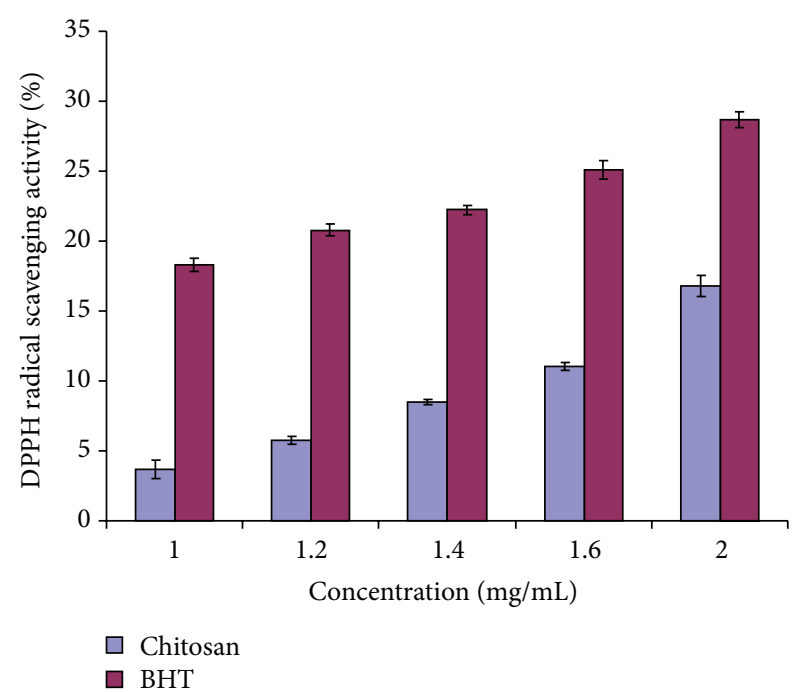

FIGURE 4: DPPH radical-scavenging activity of BHT and chitosan prepared from white shrimp waste. Data are presented as mean \pm S.D. $(n=3)$.

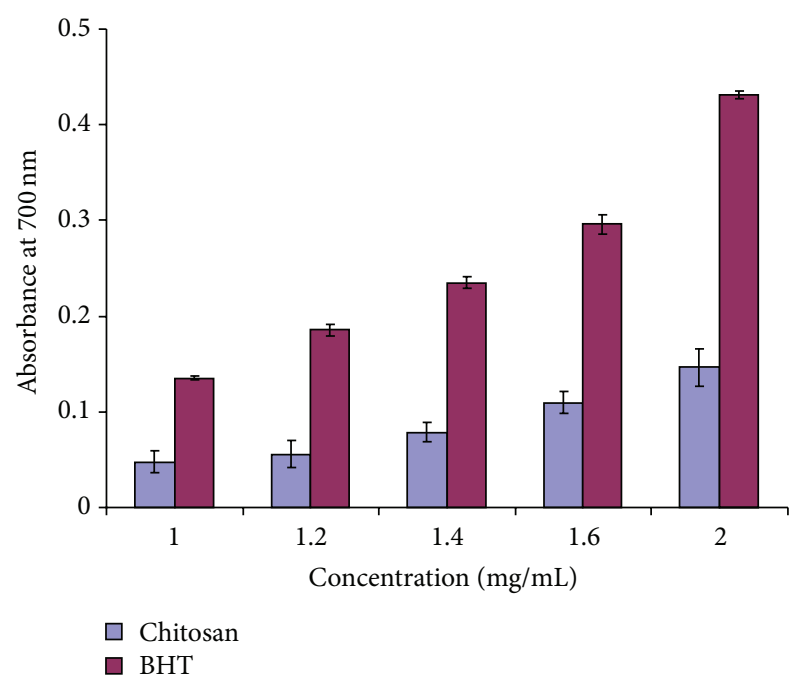

FIGURE 5: Total reducing power ability of BHT and chitosan prepared from white shrimp waste. Data are presented as mean \pm S.D. $(n=3)$.

The total reducing power ability of the chitosan was assessed based on the measurement of $\mathrm{Fe}^{3+}-\mathrm{Fe}^{2+}$ transformation. The ability exhibited a dose-dependent activity between $1.0 \mathrm{mg} / \mathrm{mL}$ and $2.0 \mathrm{mg} / \mathrm{mL}$ (Figure 5). In comparison with the BHT, the total reducing power ability of the chitosan remained significantly lower $(P<0.05)$ at the same concentration.

The antioxidative activity against lipid peroxidation in homogenates of tuna dark muscle is shown in Figure 6. Lipid peroxidation inhibition activity of the chitosan was lower $(P<0.05)$ than that of BHT at the same concentration. The activity varied from 1.7 to $15.1 \%$, which corresponds to 1.0 to $2.0 \mathrm{mg}$ of the chitosan per $\mathrm{mL}$. It is generally considered 


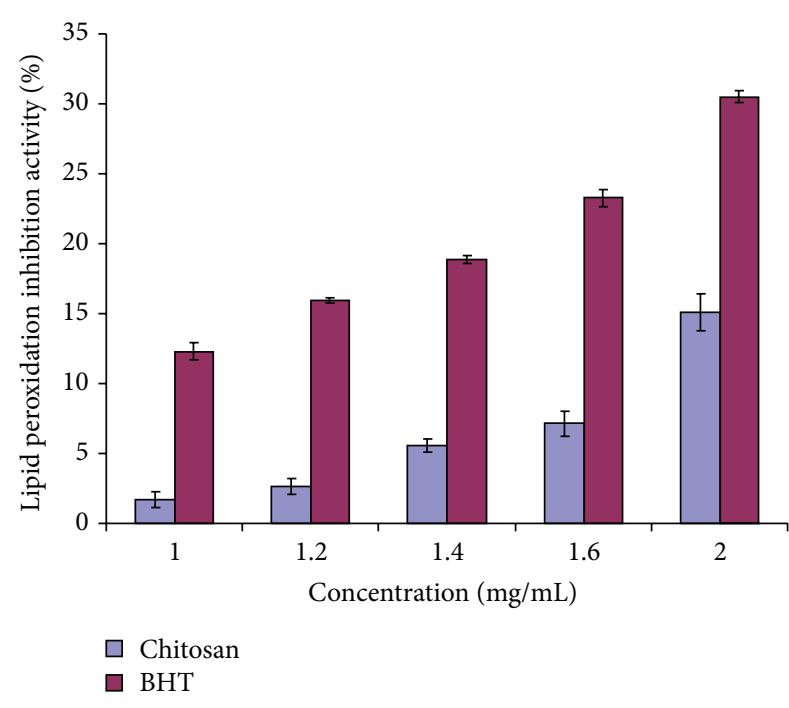

FIGURE 6: Lipid peroxidation inhibition activity of BHT and chitosan prepared from white shrimp waste. Data are presented as mean \pm S.D. $(n=3)$.

that the inhibition of lipid peroxidation by an antioxidant can be explained through various mechanisms. One such mechanism is the free radical scavenging activity and another is reducing power ability. The homogenate of tuna dark muscle in the present study is a simulated biological model where lipid oxidation was initiated by $\mathrm{FeCl}_{3} /$ sodium ascorbate in the presence of the inherent $\mathrm{Mb}$ of the muscle. When lipid hydroperoxides are generated from the lipid oxidation process, they react with the metMb that exists in the homogenate to form ferrylmyoglobin (ferrylMb) [21], which has the ability to abstract a hydrogen atom from lipids to generate an alkyl radical. In the presence of oxygen, the alkyl radical then forms a peroxyl radical, which can produce further initiatory oxidation of other lipid molecules [27]. When the chitosan was added to the homogenate, the free radicals generated from the reaction between lipid hydroperoxides and metMb in the homogenate could be scavenged by the chitosan, and the ferrylMb formed from these reactions received electrons from the $\mathrm{NH}_{2}$ group of the chitosan returning metMb. Thus, lipid peroxidation in the homogenate can be suppressed.

The present study demonstrated a significant correlation between the lipid peroxidation inhibition activity and the DPPH radical scavenging activity and total reducing power ability of the chitosan with determination coefficients of 0.98 and $0.97(P<0.05)$, respectively. This suggests that, in this particular case, the predominant mechanism of the antioxidative activity of the chitosan against lipid peroxidation in the homogenates of tuna dark muscle was based on the radical scavenging activity and reducing power ability.

\section{Conclusions}

The results show that chitin and chitosan can be prepared from white shrimp waste, which is abundant in Vietnam. The chitin and chitosan acquired were of good quality and possessed antioxidant activity which could be useful for a broad range of applications. This study identifies opportunities to develop value added products from crustacean processing by-products with biological activity such as antioxidant properties.

\section{Conflict of Interests}

The authors declare that there is no conflict of interests regarding the publication of this paper.

\section{Acknowledgments}

This research was supported by the Ministry of Education and Training, Vietnam, via a grant to Dr. Trang Si Trung. The authors would like to express their thanks to Mr. Khong Trung Thang and Mr. Nguyen Cong Minh for supporting their lab work.

\section{References}

[1] S. Hirano, "Chitin biotechnology application," Biotechnology Annual Review, vol. 2, pp. 237-258, 1996.

[2] M. N. V. R. Kumar, "A review of chitin and chitosan applications," Reactive and Functional Polymers, vol. 46, no. 1, pp. 1-27, 2000.

[3] M. Rinaudo, "Chitin and chitosan: properties and applications," Progress in Polymer Science (Oxford), vol. 31, no. 7, pp. 603-632, 2006.

[4] T. S. Trung, C.-H. Ng, and W. F. Stevens, "Characterization of decrystallized chitosan and its application in biosorption of textile dyes," Biotechnology Letters, vol. 25, no. 14, pp. 1185-1190, 2003.

[5] W. S. Xia, "Physiological activities of chitosan and its application in functional foods," International Journal of Food Science \& Technology, vol. 3, no. 1, pp. 77-81, 2003.

[6] J. N. Liu, Study on the hypolipidemic mechanism of chitosan [Doctor dissertation], Jiangnan university, Wuxi, China, 2008.

[7] W. Xia, P. Liu, J. Zhang, and J. Chen, "Biological activities of chitosan and chitooligosaccharides," Food Hydrocolloids, vol. 25, no. 2, pp. 170-179, 2011.

[8] E. S. Abdou, K. S. A. Nagy, and M. Z. Elsabee, "Extraction and characterization of chitin and chitosan from local sources," Bioresource Technology, vol. 99, no. 5, pp. 1359-1367, 2008.

[9] T. B. Cahú, S. D. Santos, A. Mendes et al., "Recovery of protein, chitin, carotenoids and glycosaminoglycans from Pacific white shrimp (Litopenaeus vannamei) processing waste," Process Biochemistry, vol. 47, no. 4, pp. 570-577, 2012.

[10] P. Charoenvuttitham, J. Shi, and G. S. Mittal, "Chitin extraction from black tiger shrimp (Penaeus monodon) waste using organic acids," Separation Science and Technology, vol. 41, no. 6, pp. 1135-1153, 2006.

[11] W. F. Stevens, "Production of chitin and chitosan: refinement and sustainability of chemical and biological processing. Chitin and Chitosan in life science," in Proceedings of the 8th International Conference on Chitin and Chitosan and 4th Asian Pacific Chitin and Chitosan Symposium, T. Uragami, K. Kurita, and T. Fukamizo, Eds., p. 293, Yamaguchi, Japan, 2001.

[12] D. Valderrama and J. L. Anderson, Shrimp Production Survey: Issues \& Challenges, Report to the World Bank, 2011, http://www .gaalliance.org/update/GOAL11/DiegoValderrama.pdf. 
[13] T. S. Trung and W. F. Stevens, "Recovery of chitin and protein from shrimp waste," Journal of Fisheries Science and Technology, vol. 2, pp. 3-10, 2010.

[14] T. S. Trung, W. W. Thein-Han, N. T. Qui, C.-H. Ng, and W. F. Stevens, "Functional characteristics of shrimp chitosan and its membranes as affected by the degree of deacetylation," Bioresource Technology, vol. 97, no. 4, pp. 659-663, 2006.

[15] K. M. Vårum, M. W. Anthonsen, H. Grasdalen, and O. Smidsrod, "Determination of the degree of $\mathrm{N}$-acetylation and the distribution of $\mathrm{N}$-acetyl groups in partially $\mathrm{N}$-deacetylated chitins (chitosans) by high field NMR spectroscopy," Carbohydrate Research, vol. 211, no. 1, pp. 17-23, 1991.

[16] S. C. Tan, E. Khor, T. K. Tan, and S. M. Wong, "The degree of deacetylation of chitosan: advocating the first derivative UVspectrophotometry method of determination," Talanta, vol. 45, no. 4, pp. 713-719, 1998.

[17] Y. I. Cho, H. K. No, and S. P. Meyers, "Physico-chemical characteristics and functional properties of various commercial chitin and chitosan products," Journal of Agricultural and Food Chemistry, vol. 46, no. 9, pp. 3839-3843, 1998.

[18] H. K. No, K. S. Lee, and S. P. Meyers, "Correlation between physicochemical characteristics and binding capacities of chitosan products," Journal of Food Science, vol. 65, no. 7, pp. 1134$1137,2000$.

[19] H.-Y. Fu, D.-E. Shieh, and C.-T. Ho, "Antioxidant and free radical scavenging activities of edible mushrooms," Journal of Food Lipids, vol. 9, no. 1, pp. 35-46, 2002.

[20] M. Oyaizu, "Studies on products of browning reactions: antioxidative activities of products of browning reaction prepared from glucosamine," The Japanese Journal of Nutrition and Dietetics, vol. 44, no. 6, pp. 307-315, 1986.

[21] H. N. D. Bao, Y. Ochiai, and T. Ohshima, "Antioxidative activities of hydrophilic extracts prepared from the fruiting body and spent culture medium of Flammulina velutipes," Bioresource Technology, vol. 101, no. 15, pp. 6248-6255, 2010.

[22] M. Uchiyama and M. Mihara, "Determination of malonaldehyde precursor in tissues by thiobarbituric acid test," Analytical Biochemistry, vol. 86, no. 1, pp. 271-278, 1978.

[23] R. L. Lavall, O. B. G. Assis, and S. P. Campana-Filho, “ $\beta$-Chitin from the pens of Loligo sp.: extraction and characterization," Bioresource Technology, vol. 98, no. 13, pp. 2465-2472, 2007.

[24] T. K. Sini, S. Santhosh, and P. T. Mathew, "Study on the production of chitin and chitosan from shrimp shell by using Bacillus subtilis fermentation," Carbohydrate Research, vol. 342, no. 16, pp. 2423-2429, 2007.

[25] A. Einbu and K. M. Vårum, "Characterization of chitin and its hydrolysis to GlcNAc and GlcN," Biomacromolecules, vol. 9, no. 7, pp. 1870-1875, 2008.

[26] P.-J. Park, J.-Y. Je, and S.-K. Kim, "Free radical scavenging activities of differently deacetylated chitosans using an ESR spectrometer," Carbohydrate Polymers, vol. 55, no. 1, pp. 17-22, 2004.

[27] B. J. Reeder and M. T. Wilson, "Mechanism of reaction of myoglobin with the lipid hydroperoxide hydroperoxyoctadecadienoic acid," Biochemical Journal, vol. 330, no. 3, pp. 1317-1323, 1998. 

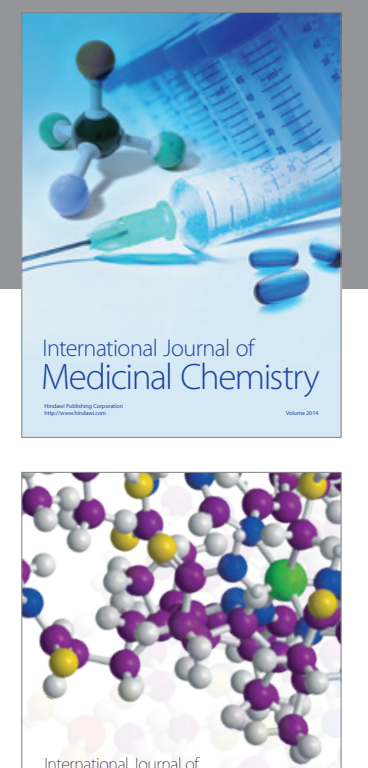

\section{Carbohydrate} Chemistry

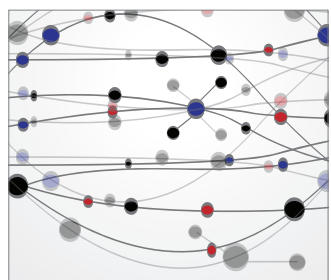

The Scientific World Journal
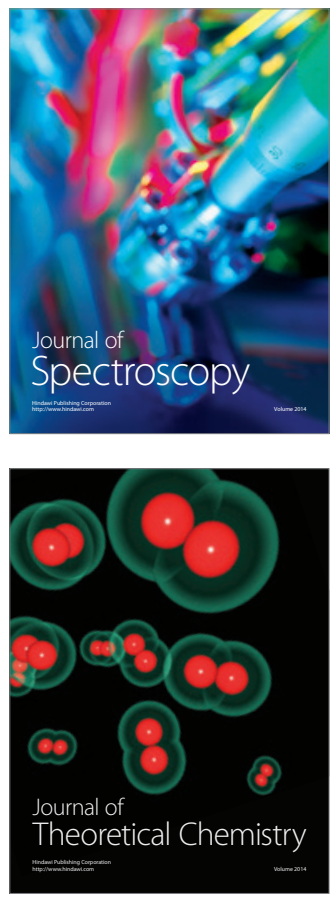
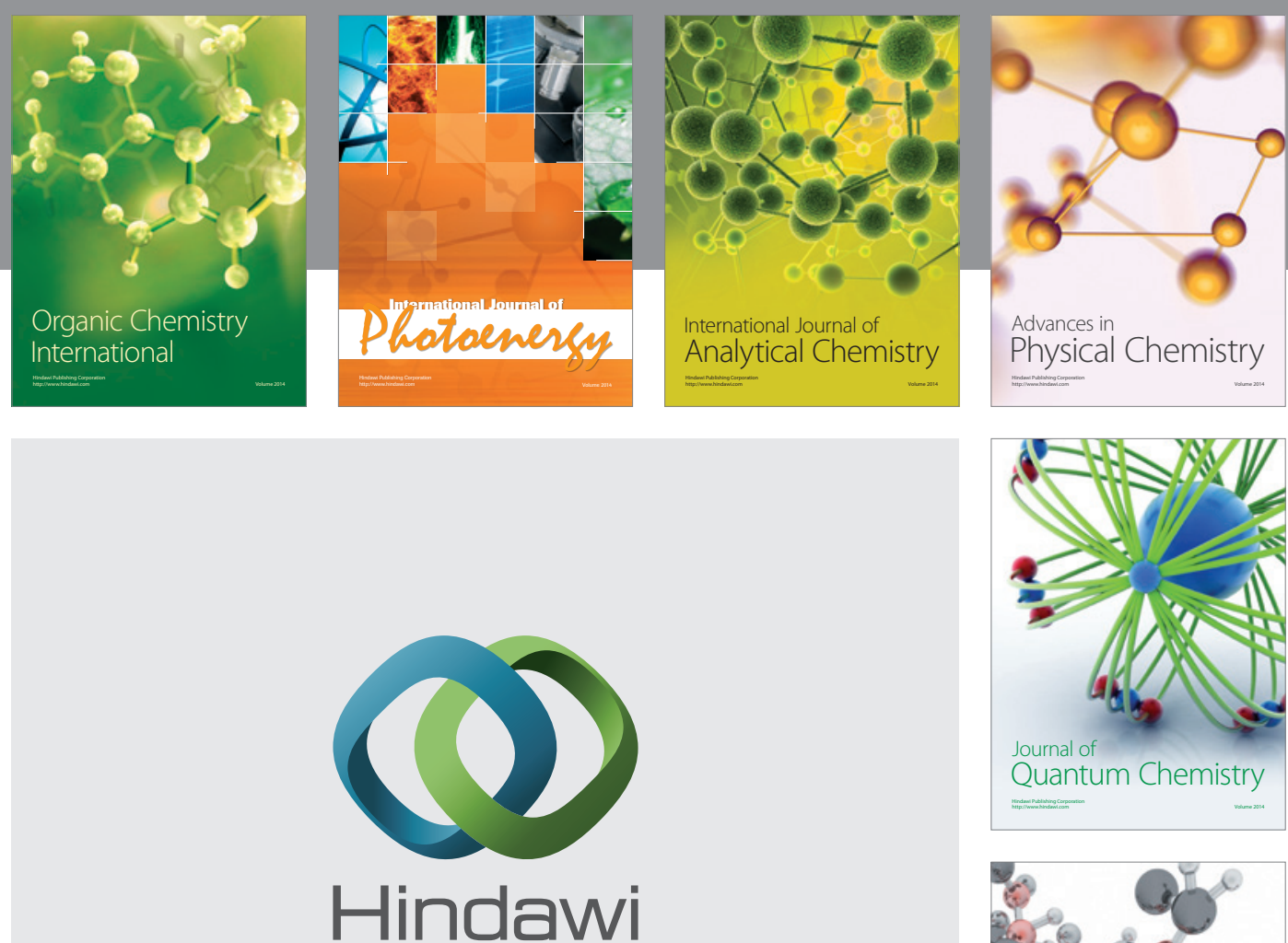

Submit your manuscripts at

http://www.hindawi.com

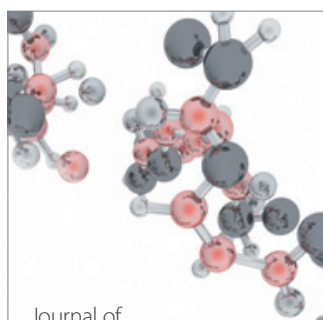

Analytical Methods

in Chemistry

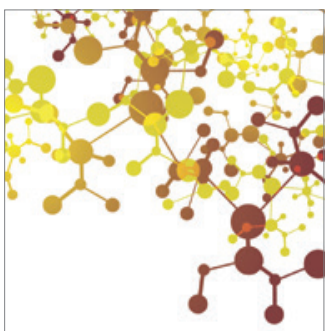

Journal of

Applied Chemistry

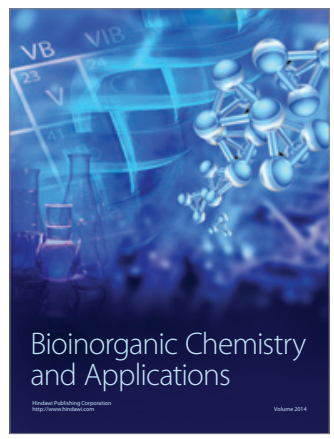

Inorganic Chemistry
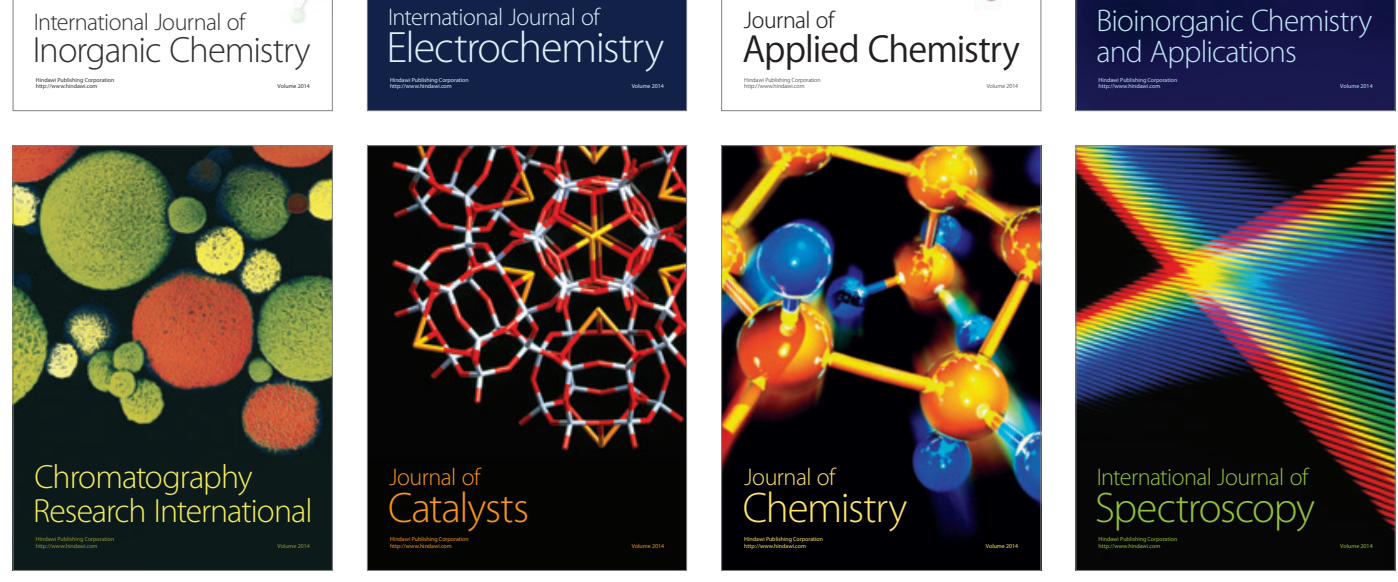